\title{
ADOÇÃO NA PASSARELA: SENTIDOS DA EXPOSIÇÃO DE CRIANÇAS E ADOLESCENTES
}

\author{
"Adoção na passarela": meanings of the exposure of children and adolescents \\ "Adoção na passarela": sentidos de la exposición de niños y adolescentes
}

Andrielly Silva Ramos de Sene Bolsista de Iniciação Científica na Universidade Federal de Mato Grosso andriellysene@gmail.com

Dôuglas Aparecido Ferreira Professor da Faculdade de Comunicação e Artes da Universidade Federal de Mato Grosso douglasferreira@ufmt.br

Pâmela Saunders Uchôa Craveiro Professora de Pós-Graduação em Comunicação da Universidade Federal de Mato Grosso pamelacraveiro@ufmt.br

\section{Resumo}

Este artigo tem por objetivo analisar os sentidos em torno da participação de crianças e adolescentes no evento Adoção na Passarela, o qual repercutiu nos meios de comunicação e impulsionou um debate sobre direitos na infância e juventude. A partir desse acontecimento, identificou-se os quadros de leitura em disputa nos comentários de uma notícia sobre o evento. Para tanto, discutiu-se sobre adoção, assim como articulou-se os conceitos de acontecimento e produção de sentido. Metodologicamente, realizou-se uma análise de conteúdo, no intuito de se investigar os sentidos presentes nas categorias de leituras propostas por Hall (2003). A análise revelou um quadro simbólico que diz sobre nosso tempo, ao manifestar o reconhecimento da fragilidade na garantia dos direitos de crianças e adolescentes no Brasil.

Palavras-chave: Infância e Adolescência. Produção de Sentido. Acontecimento.

\begin{abstract}
This paper aims to examine the meanings around the participation of children and adolescents in "Adoção na Passarela" event, which reverberated in the media and spurred a debate about rights in childhood and youth. From that event, frames of interpretation were identified in the comments of an online news about the event. The adoption was discussed, as well as the concepts of event and production of meanings. Methodologically, a content analysis was carried out to investigate the meanings present in the frames of interpretation proposed by Hall (2003). The analysis disclosed a symbolic frame that says about our time, when expressing the recognition of the fragility in guaranteeing the rights of children and adolescents in Brazil.
\end{abstract}

Key words: Childhood and Adolescence. Production of meanings. Event. 


\section{Resumen}

Este artículo tiene como objetivo analizar los sentidos que rodean la participación de niños, niñas y adolescentes en el evento "Adopción en la Pasarela", que reverberó en los medios de comunicación y estimuló un debate acerca de los derechos en la infancia y la adolescencia. Para ello, fueron identificadas las lecturas en disputa en los comentarios de una noticia acerca del evento. Teóricamente, fueron discutidos el tema de adopción, así como los conceptos de acontecimiento y producción de sentido. Metodológicamente, fue realizado un análisis de contenido para investigar los sentidos presentes en las categorías de lecturas propuestas por Hall (2003). El análisis reveló aspectos de nuestro tiempo, al expresar el reconocimiento de la fragilidad en la garantía de los derechos de los niños y adolescentes en Brasil.

Palabras clave: Infancia y Adolescencia. Producción de Sentido. Acontecimiento.

\section{INTRODUÇÃO}

Há mais de 47 mil crianças e adolescentes institucionalmente acolhidas no Brasil. Desses, apenas 4.772 estão efetivamente aptos à adoção ${ }^{1}$, enquanto existem mais de 46 mil pretendentes (CONSELHO NACIONAL DE JUSTIÇA, 2020). Ou seja, para cada criança ou adolescente disponível à adoção, há mais de nove pessoas interessadas em acolhê-las. No entanto, $58 \%$ dos pretendentes aceitam apenas crianças de até quatro anos de idade, o que constitui uma discrepância com a realidade, uma vez que 53,53\% possuem entre 10 e 17 anos e, portanto, não se enquadram nessa exigência (OBSERVATÓRIO DO TERCEIRO SETOR, 2019). Esse quadro revela uma grande dificuldade de se concretizar processos de adoção tardia no Brasil, aqueles caracterizados por envolverem crianças que tenham idade superior a quatro anos (MENEGATI; SOMMER, 2017).

Nesse cenário, dar visibilidade à causa da adoção (sobretudo a tardia) tem sido uma preocupação constante de entidades que trabalham com a temática. No entanto, observa-se que algumas dessas iniciativas têm focado na divulgação "maciça e irrestrita da imagem e da disponibilidade à adoção de crianças e adolescentes" (NAKAMURA, 2019, p. 193), muitas vezes, deixando para segundo plano a devida preocupação com os direitos fundamentais desses indivíduos e contribuindo para sua “coisificação” (NAKAMURA, 2019).

Nosso interesse neste artigo é analisar uma iniciativa que se insere nesse contexto e que repercutiu nacionalmente. Trata-se da segunda edição do evento Adoção na Passarela ${ }^{2}$

\footnotetext{
${ }^{1}$ Crianças e adolescentes tornam-se aptos à adoção após falhas nas tentativas de reinserção na família de origem. Ou ainda se não houver possibilidade de ficarem com a família extensa (por exemplo, tios e avós).

${ }^{2}$ Uma primeira edição, sem tanta repercussão, ocorreu em 2016.
} 
que aconteceu em Cuiabá (MT), no dia 21 maio de 2019, e foi promovido pela Associação Matogrossense de Pesquisa e Apoio à Adoção (AMPARA), em parceria com a Ordem dos Advogados do Brasil - Seccional Mato Grosso (OAB-MT), além de ter tido autorização da $1^{\mathrm{a}}$ Vara Especializada da Infância e Juventude do mesmo estado. Na ocasião, crianças e adolescentes (de quatro a dezessete anos) aptos a serem adotados, após serem maquiados, terem seus cabelos e roupas produzidos (MERCURI, 2019), desfilaram em uma passarela para uma plateia de aproximadamente duzentas pessoas no interior de um shopping ${ }^{3}$.

Ao ser noticiado em um portal on-line de notícia da cidade, o desfile alcançou mais pessoas do que aquelas que estiveram no dia do evento e impulsionou um debate sobre o limite tênue entre a visibilidade da causa da adoção e a exposição de crianças e adolescentes. A discussão se fez presente nas seções de comentários dos portais, em sites de redes sociais e em programas televisivos com ampla audiência nacional, como Fantástico e Encontro com Fátima Bernardes, ambos da TV Globo. Diante da repercussão do caso, o Fundo das Nações Unidas para a Infância publicou uma nota, repudiando a iniciativa por ferir os direitos das crianças e adolescentes participantes. Também se posicionaram publicamente contra o evento a Defensoria Pública de Mato Grosso e o Conselho Regional de Psicologia do estado (CRPMT). Em resposta às críticas, a OAB-MT e a AMPARA publicaram uma nota de esclarecimento em conjunto, expondo que a intenção da ação era estimular a adoção tardia.

Neste artigo, nos interessa investigar os sentidos compartilhados sobre o evento Adoção na Passarela, entendendo o desfile como um acontecimento que engajou diversos públicos e suscitou várias leituras. Primeiramente, apresentamos um breve panorama dos direitos da infância e da adolescência. Em seguida, discutimos sobre a problemática da adoção e os desafios para a visibilidade da causa. Posteriormente, articulamos os conceitos de acontecimento de modo a fundamentar a análise dos sentidos circulantes sobre infância e adolescência a partir do evento estudado. Metodologicamente, realizamos uma análise de conteúdo (BARDIN, 2010), com abordagem qualitativa, no intuito de investigar, por meio das recorrências das ligações lexicais, os sentidos presentes nos tipos de leitura propostos por Hall (2003): hegemônicas, negociadas e de oposição. Por fim, nas considerações, apresentamos uma discussão sobre os resultados das análises, problematizando a tensão entre a exposição de crianças e adolescentes e a reivindicação de visibilidade para a causa da adoção.

\footnotetext{
${ }^{3}$ Ver mais detalhes sobre o evento em: <bbc.in/3djKQjE〉. Acesso em: 18 maio 2020 e em: <glo.bo/3chfitr〉. Acesso em: 18 maio 2020.
} 
Essa empreitada investigativa se justifica à medida em que possibilita a apreensão da dinâmica dos movimentos da sociedade e das escolhas dos sujeitos em interação aos conteúdos da mídia. É através de sua dimensão hermenêutica, isto é, na sua capacidade de revelar valores e sentidos, que a interpretação de um acontecimento é potente no entendimento de suas consequências na sociedade, revelando que, para além do fato relatado, há um quadro simbólico que diz sobre nosso tempo.

\section{INFÂNCIA E ADOLESCÊNCIA: SISTEMAS DE GARANTIA DE DIREITOS NO BRASIL E NO MUNDO}

Ao se falar de crianças e adolescentes, é importante refletir acerca da construção histórica, social e discursiva dos conceitos de infância e adolescência ${ }^{4}$ (ARIÈS, 1981; QVORTRUP, 2010; HEYWOOD, 2004). Esses, embora tão naturalizados em nossa cultura, não são universais. Nesse sentido, as concepções hoje dominantes do que é ser criança e adolescente nem sempre existiram. Na verdade, elas vêm se modificando ao longo do tempo a partir das formas de organização social de cada época (KRAMER, 2008), bem como "do resultado de uma complexa rede de inter-relações entre ideologia, governo, pedagogia e tecnologia" (BUCKINGHAM, 2000, p. 59).

Assim, são frequentes as negociações e tensões entre diversos atores sociais acerca do significado de infância e adolescência, produzindo sentidos que colaboram para delinear a posição ocupada por crianças e adolescentes na sociedade. Inclusive na agenda de políticas públicas, a qual não deixa de ser também uma construção social (ROSEMBERG; MARIANO, 2010).

Nessa perspectiva, a necessidade de garantir o bem-estar e a proteção na infância e na adolescência são preocupações relativamente recentes. Somente em 1924, na Declaração de Genebra em favor dos menores de idade, foi manifestada internacionalmente, pela primeira vez, "a necessidade de proporcionar à criança uma proteção especial” (MOMBERGER, 2002, p. 37). Em seguida, em 1959, aconteceu um marco nos direitos da infância quando a Organização das Nações Unidas (ONU) promulgou a Declaração Universal dos Direitos da Criança. Pela primeira vez na história, a criança foi considerada prioridade absoluta e sujeito

\footnotetext{
${ }^{4}$ Neste artigo, ao mencionarmos crianças e adolescentes, estamos seguindo a classificação adotada pelo Estatuto da Criança e do Adolescente (ECA) que, em seu artigo $2^{\circ}$, considera criança a pessoa até doze anos incompletos e adolescente aquela que possui entre 12 e 18 anos.
} 
de Direito (MARCílIO, 1998). Trinta anos depois, em 1989, ocorreu a Convenção das Nações Unidas sobre os Direitos da Criança, que tem como princípios básicos o estabelecimento da proteção especial de crianças como seres em desenvolvimento e a obrigação de constituí-las como prioridade absoluta. Nesse evento, foi considerada criança todos aqueles com idade inferior a 18 anos. Instituída nos princípios da Declaração Universal dos Direitos Humanos (1948) e na Declaração Universal dos Direitos da Criança (1959), essa Convenção é o instrumento de direitos humanos mais aceito na história universal, ratificado por 196 países, entres eles o Brasil (UNICEF, 20-?).

O Brasil promulgou a Convenção da ONU sobre os Direitos da Criança em 1990, por meio do Decreto Legislativo 99.710, transformando-a em lei interna (MOMBERGER, 2002). Entretanto, a adequação aos preceitos da Convenção precede-a. "Ela está positivada em nossa Carta Constitucional de 1988, principalmente em seus artigos $227^{5}, 228^{6}$ e $229^{7}$, que seguiram a doutrina da Declaração dos Direitos da Criança, de 1959” (MARCÍLIO, 1998, p. 50-51).

O Estatuto da Criança e do Adolescente (ECA), assinado em 1990, assumiu o importante papel de regulamentar os dispositivos previstos na Constituição Brasileira de 1988 em favor da infância. Formulado por meio de ampla participação do governo e de organizações civis (OAB - Ordem dos Advogados do Brasil, UNICEF, Movimento Nacional dos Meninos de Rua, Pastoral do Menor, movimentos de igrejas e universidades, para citar alguns exemplos), o ECA "representa uma verdadeira revolução em termos de doutrina, ideias, práxis, atitudes nacionais ante a criança” (MARCÍLIO, 1998, p. 51). Nos artigos $1^{\circ}$ e $4^{\circ}$, respectivamente, estabelece o princípio de proteção integral e a prioridade absoluta a crianças e adolescentes. Ademais, no artigo 17, está assegurado o direito à inviolabilidade física, psíquica e moral, à preservação da imagem e da identidade. Por sua vez, no artigo 18, é determinado como "dever de todos velar pela dignidade da criança e do adolescente, pondo-os a salvo de qualquer tratamento desumano, violento, aterrorizante, vexatório ou constrangedor" (BRASIL, 1990).

O país, portanto, apresenta consistentes instrumentos legais para a defesa dos direitos de crianças e adolescentes resultantes de reivindicações históricas (MBAYA, 1997).

\footnotetext{
${ }^{5}$ É dever da família, da sociedade e do Estado assegurar à criança, ao adolescente e ao jovem, com absoluta prioridade, o direito à vida, à saúde, à alimentação, à educação, ao lazer, à profissionalização, à cultura, à dignidade, ao respeito, à liberdade e à convivência familiar e comunitária, além de colocá-los a salvo de toda forma de negligência, discriminação, exploração, violência, crueldade e opressão.

${ }^{6}$ São penalmente inimputáveis os menores de dezoito anos, sujeitos às normas da legislação especial.

${ }^{7}$ Os pais têm o dever de assistir, criar e educar os filhos menores, e os filhos maiores têm o dever de ajudar e amparar os pais na velhice, carência ou enfermidade.
} 
Entretanto, como mencionado, as concepções de infância e adolescência, assim como a construção da agenda pública de problemas sociais referentes a essa temática, são constantemente negociadas e influenciadas pelas dinâmicas estabelecidas nos âmbitos político e social. Como afirmam Rosemberg e Mariano (2010, p. 697), hierarquizamos "problemas sociais conforme padrões éticos, políticos, orientações ideológicas, interesses pessoais ou corporativos". Atualmente, é preciso considerar ainda o papel central que os meios de comunicação exercem na construção da agenda desses problemas sociais.

\section{A PROBlemática da AdOÇÃo E A VISIBILIDAdE DA CAUSA NA Mídia BRASILEIRA}

No Brasil, a problemática da adoção vem desde a época da colonização, quando a prática era socialmente compreendida como uma espécie de auxílio dos mais riscos às pessoas financeiramente desfavorecidas. Os ditos "filhos de criação" eram comumente vistos no interior de casas de pessoas ricas. Entretanto, a permanência deles no leito familiar não era formalizada e tendia a ser encarada como oportunidade de possuir mão de obra gratuita mascarada de caridade (MAUX; DUTRA, 2010). Essa prática contribuiu para que tabus e preconceitos relacionados à adoção fossem construídos e enraizados na sociedade. A desconstrução desse imaginário negativo tornou-se um dos principais objetivos da luta histórica por formalizar os processos de adoção no país. No entanto, resquícios ainda são percebidos séculos depois.

Pesquisas (WEBER et al., 1994; WEBER; CORNÉLIO, 1995; WEBER; GAGNO, 1995) apontam como "especialmente os brasileiros ainda esbarram na barreira irracional das crendices" (WEBER, 1995, p. 2-3) quando o assunto é adoção. Esses estudos revelam, por exemplo, que as pessoas costumam pensar que: (i) uma criança que viveu muito tempo em orfanatos desenvolve "vícios" e trará problemas cedo ou tarde; (ii) crianças com mais de seis meses de idade são mais difíceis de educar; (iii) a criança que não sabe que é adotiva traz menos problemas para a família, então, quanto mais nova, mais fácil seria esconder sua história; e (iv) adoções feitas por meio de Juizados são burocráticas e discriminatórias.

Essa problemática é regulamentada pela Lei $\mathrm{n}^{\circ}$ 12.010/2009, conhecida como Lei Nacional da Adoção, a qual alterou cinquenta e quatro artigos do ECA (Lei n 8.060/1990) e estabeleceu importantes inovações legislativas no que tange ao tema adoção no país (CASSANHA; GARCIA, 2013). Em 2017, o ECA sofreu mais uma alteração nesse âmbito 
com a Lei $n^{\circ} 13.509$, que dispõe "sobre entrega voluntária, destituição do poder familiar, acolhimento, apadrinhamento, guarda e adoção de crianças e adolescentes” (BRASIL, 2017). No entanto, como exposto na introdução deste artigo, as leis não são suficientes para solucionar o descompasso entre os critérios desejáveis pela maioria de pessoas com interesse em adotar e o número de crianças e adolescentes aptos à adoção.

Com o intuito de dar maior visibilidade à causa, entidades que trabalham com a temática realizam ações visando a conscientização da sociedade - como caminhadas ${ }^{8}$, palestras, atividades em parques ${ }^{9}$, exposições ${ }^{10}$, campanhas publicitárias $^{11}$, criação de aplicativos móveis ${ }^{12}$ e até promoção de desfiles protagonizados por crianças e adolescentes, como é o caso do objeto deste estudo. No entanto, considerando-se que os meios de comunicação têm expressiva participação na construção da realidade contemporânea, é preciso ressaltar o papel que exercem na percepção da população sobre a adoção. Ainda que se reconheça a necessidade de ampliar as pesquisas que tratam da relação mídia e prática adotiva (GAGNO; WEBER, 2003), é possível problematizá-la a partir das contribuições de alguns autores.

Weber $(1996,1998)$ aponta a responsabilidade da mídia na criação e manutenção de preconceitos sociais a respeito da adoção. Para a autora, isso acontece porque os veículos optam por focar somente nos casos em que ocorreram dificuldades no processo, "formando-se desta maneira uma representação social limitada e errônea sobre a associação genérica entre adoção e fracasso" (WEBER, 1998, p. 98).

Em relação à cobertura jornalística em específico, Gagno (2002) verifica uma tendência em apresentar a adoção, respectivamente nas revistas Pais \& Filhos e Veja, em duas perspectivas: uma mais emocional e outra com o foco informativo. Abreu (1998) aponta o interesse da mídia impressa (centrando sua análise no jornal O Povo) em abordar a adoção internacional, que é representada como um "mal necessário" diante da suposta incapacidade

\footnotetext{
${ }^{8}$ IBDFAM. 25 de maio - Dia Nacional da Adoção: é preciso dar visibilidade aos que esperam por um lar. IBDFAM. 2019. Disponível em: <bit.ly/2TQYV03>. Acesso em: 19 maio 2020.

${ }^{9}$ SANTOS, Helene. Evento dá visibilidade à causa de adoção. Diário do Nordeste, Fortaleza, 17 dez. 2017. Disponível em: <bit.ly/3dv7Dcx>. Acesso em: 19 maio 2020.

${ }^{10}$ TJES, Tribunal de Justiça do Estado do Espírito Santo. Poder judiciário realiza ações no Dia Nacional da Adoção, comemorado nesta quinta-feira. 2017. Disponível em: 〈bit.ly/2AnmwPm〉. Acesso em: 19 maio 2020.

${ }^{11}$ TJBA, Tribunal de Justiça do Estado da Bahia. 25 de maio: Dia Nacional da Adoção! Compartilhe desta ideia. 2018. Disponível em: 〈bit.ly/2TTDADo〉. Acesso em: 20 maio 2020.

${ }^{12}$ TJPR. De invisíveis para visíveis: o aplicativo A.DOT foi o responsável por garantir uma chance a mais às crianças e adolescentes que estão em busca de um lar. 2019. Disponível em <bit.ly/2XLG7AM>. Acesso em: 28 mai 2020.
} 
do Brasil de criar suas crianças. Por sua vez, Costa e Braga (2019), ao estudarem a cobertura do jornal Folha de S. Paulo, identificam um destaque do veículo para a burocracia enfrentada por quem decide adotar.

Mas, não são somente os jornais que influenciam a percepção sobre adoção. Ayres (2016), ao analisar os discursos e práticas relacionados à adoção em telenovelas da Rede Globo, constata que a teledramaturgia brasileira, ao longo dos anos, vem produzindo narrativas pró-adoção que contribuem para que o debate social acerca da prática adotiva tenha maior alcance.

Diante do exposto, é possível perceber como a adoção é abordada de formas distintas pelos meios de comunicação, a depender do interesse que se tenha pela temática. Mais do que dar visibilidade à causa, a mídia também pode ser responsável pela criação ou até mesmo manutenção de estereótipos e preconceitos. Tal entendimento destaca o papel que os meios de comunicação têm de "possibilitar uma reorientação nos conceitos e práticas sociais, inclusive sobre a adoção, com base na divulgação de notícias completas e críticas sobre os fatos, ao invés de enrijecer ainda mais os preconceitos populares" (GAGNO; WEBER, 2003, p. 116).

Essa discussão contribui para a compreensão da iniciativa Adoção na Passarela e sua repercussão como um acontecimento não isolado e que, portanto, faz parte de um contexto mais amplo que envolve a relação entre mídia e representação da prática adotiva. À vista disso, ao passo que o evento engajou diversos públicos, também suscitou diferentes leituras sobre a questão do limite da exposição de crianças e adolescentes para dar visibilidade à causa da adoção. Assim, no intuito de aprofundar a reflexão sobre o assunto, faz-se necessário discutir acerca dos conceitos: acontecimento e produção de sentido, e como eles se relacionam no ambiente midiático contemporâneo. Essa reflexão será somada a ideia de tipos de leitura proposta por Hall (2003). Esses conceitos serão utilizados como operadores analíticos do objeto estudado.

\section{CAMINHO METOdOLÓGICO: O ACONTECIMENTO E A EMERGÊNCIA DAS LEITURAS EM DISPUTA}

Há uma relação próxima entre os conceitos teóricos: acontecimento e produção de sentidos, principalmente quando se olha para o contexto das mídias. Nesse caso, acontecimento deixa de ser sinônimo de um fenômeno banal da vida cotidiana e passa a ser utilizado para representar "os fatos e as ocorrências que se destacam ou merecem maior 
destaque" (FRANÇA, 2012, p. 12) do ponto de vista das organizações midiáticas. A autora citada explica que o conceito é bastante significativo para o campo da Comunicação, principalmente na prática jornalística, "que se constrói exatamente em torno dos acontecimentos" (FRANÇA, 2012, p. 13). Desse modo, os fatos que merecem ser noticiados seriam os "acontecimentos", isto é, sua ocorrência é narrada através de um quadro de sentido que lhe atribua status de "noticiável". Logo, um evento se transforma em acontecimento tanto pela sua relevância quanto porque ganha uma forma particular de ser contado e repercutido pela mídia.

França (2012) ainda atesta que o acontecimento rompe a normalidade; ele quebra uma sequência, desorganiza, penetra sem aviso prévio e gera impasses. Em termos gerais, o desdobramento de um acontecimento é sempre uma incógnita, e é essa característica que faz com que o acontecimento provoque produções de sentidos, uma vez que ele leva à reflexão, intriga, revela pontos ainda não percebidos e incita questões que convocam antigos e novos aspectos para respondê-las. Em suma, "acontecimentos não são simples ocorrências, mas fatos que têm um poder de afetação, que acontecem a alguém, provocam sentidos, convocam o passado, reorientam o futuro" (FRANÇA, 2012, p. 17).

Portanto, entende-se que o acontecimento não pode ser definido como somente um espetáculo midiático com sentidos introduzidos para influenciar ou alienar uma audiência; ele também se insere em um movimento interacional e provoca outros sentidos na instância de recepção. São nas arenas do debate público que esses sentidos se reordenam, são ressignificados e estimulam ações da ordem do enfrentamento, do consentimento e da negociação (MENESES, 2010).

Partindo do pressuposto de que a comunicação é um processo relacional entre interlocutores que produzem, trocam, compartilham e disputam sentidos dentro de um contexto específico sobre o qual agem e padecem (FRANÇA, 2001), reivindica-se a importância do entendimento da dinâmica de afetação que perpassa aqueles que se sentem provocados por um acontecimento, entendendo a influência do contexto e a tensão dos sentidos produzidos pelos envolvidos. Assim, assumir o caráter interacional do acontecimento significa pensá-lo como um processo em que os sentidos propostos pela mídia certamente afetam os sujeitos, mas também ganham novos contornos a partir do contexto das experiências sociais e dos valores compartilhados intersubjetivamente pelas pessoas. Contexto e valores sociais fazem os sujeitos se sentirem engajados a um determinado posicionamento e dão inteligibilidade às coisas com as quais eles lidam e às ações que empreendem. Desse 
modo, "não são os sentidos que advém para iluminar o fato e convertê-lo em acontecimento: o acontecimento o é porque é capaz de desencadear sentidos" (FRANÇA; ALMEIDA, 2006, p. $4)$.

A perspectiva praxiológica da interação, central no pensamento de Dewey (1954), ajuda a entender como os públicos se engajam a um determinado acontecimento. Para o pragmatista, os públicos emergem contextualmente na medida em que várias pessoas são afetadas direta ou indiretamente por uma situação e respondem socialmente, de forma ordenada ou não, a ela. Os públicos, portanto, são vistos como formações heterogêneas, dinâmicas e compostas por uma variedade de inclinações e interesses. É assim que um público se constitui, na dicotomia entre ser paciente e agente, em sofrer e agir.

Essa noção de público nos permite levantar a questão central que direciona os objetivos deste artigo. Isto é, uma vez que os públicos se constituem a partir da afetação provocada pelo evento Adoção na Passarela, é possível investigar a configuração dos diferentes posicionamentos assumidos pelos sujeitos, entendendo que estes são influenciados pelo contexto sociocultural em que se encontram e os valores sociais que compartilham. As conversações que se originam desse cenário de consensos e dissensos é o que constitui o debate público sobre o assunto, um componente que contribui para a complexificação de um acontecimento, trazendo novos sentidos para a narrativa midiática por meio da apropriação e reconfiguração das matrizes interpretativas do fato relatado. Os públicos, que se encontram na arena de debate, podem ser identificados por análises empíricas destinadas a apreender a fala de leitores dos produtos midiáticos e, assim, a verificar como eles se posicionam em relação ao acontecimento.

Partindo da ideia de que a mídia funciona como um espaço em que acontecimentos são repercutidos e adquirem sua segunda vida (FRANÇA, 2012), analisamos os sentidos disputados pelos comentários da notícia sobre o evento Adoção na Passarela publicada no portal Olhar Conceito (MERCURI, 2019). A escolha desse fragmento justifica-se por ter sido uma notícia de divulgação do evento que antecedeu a repercussão nacional e, inclusive, ao ser compartilhada por pessoas de diversas partes do país, estimulou o debate nas redes sociais.

O corpus de análise é composto por 331 comentários $^{13}$, frações dos diálogos travados na esfera pública a respeito do episódio aqui em questão, os quais foram explorados a partir

\footnotetext{
${ }^{13}$ Para compor o corpus, consideramos somente os comentários publicados em 22 de maio de 2019, um dia depois do evento, quando o debate se intensificou. Ademais, eliminamos aqueles que não se referiam especificamente ao assunto pois tratavam de questões pessoais (ex.: "estou com vontade de adotar. Sou mãe de um adolescente", "como faz para adotar", "tenho vontade de adotar um adolescente" etc.).
} 
da perspectiva de Hall (2003, p. 354) de que o "sentido sempre possui várias camadas, [...] é sempre multirreferencial”. Desse modo, de acordo com o autor, o campo da recepção pode ser categorizado em três planos de leitura: hegemônicas-dominantes, negociadas e de oposição.

Consideramos leituras hegemônicas os comentários que tendem a convergir com as intenções dos enunciadores (AMPARA e OAB-MT, instituições promotoras do evento). Identificamos como leituras negociadas aquelas que apresentaram em parte elementos das ideias centrais e dominantes, mas também novas possibilidades de significação do evento, distintas daquelas pretendidas pelos enunciadores. Por fim, classificamos como leituras de oposição, os comentários em que o público evidenciou a discordância com as intenções dos enunciadores, partindo de referências distintas àquelas propostas no evento e desconstruindo as tendências dominantes.

As intenções dos promotores do evento foram explicitadas na notícia do Olhar Conceito e na nota de esclarecimento divulgada após a repercussão do acontecimento. Nesses textos, afirma-se que o objetivo do desfile foi "dar visibilidade a crianças e adolescentes de 4 a 17 anos, que estão aptas para adoção" (MERCURI, 2019), assim como "promover a convivência social e mostrar a diversidade da construção familiar por meio da adoção com a participação das famílias adotivas” (AMPARA; OAB-MT, 2019).

Argumentos contrários foram identificados nas notas de repúdio expedidas pela UNICEF, Defensoria Pública do Mato Grosso e Conselho Regional de Psicologia de Mato Grosso (CRP-MT). De modo geral, as entidades defendem que "crianças e adolescentes foram expostos publicamente. Essa exposição diverge do processo humanizado de adoção e viola os direitos humanos no contexto da infância e adolescência" (CRP-MT, 2019). Há também preocupação com os danos emocionais provocados pelo evento, uma vez que "é evidente que a maioria dessas crianças e adolescentes não será adotada, o que evidentemente gerará sérios sentimentos de frustração, prejuízos à estima e indeléveis impactos psicológicos" (DEFENSORIA PÚBLICA DE MATO GROSSO, 2019). E, ainda, a defesa do cumprimento do Estatuto da Criança e do Adolescente "que prioriza a proteção, a confidencialidade e a privacidade dentro dos processos envolvidos para a restituição do direito a viver em família" (UNICEF, 2019).

A notícia e as notas públicas de apoio e repúdio ajudaram a mapear os principais sentidos contra-hegemônicos, hegemônicos e negociados que envolveram o acontecimento na instância da emissão e circulação. Os comentários foram categorizados em três grupos constituídos por meio de critérios que mostrassem articulação entre eles e os tipos de leitura. 
Em complementariedade a isso, foram criados subgrupos semânticos a partir de informações coletadas da análise qualitativa das unidades de vocabulário, identificando nelas traços de ordenação e combinação frequencial (BARDIN, 2010).

O quadro a seguir apresenta as informações quantitativas do corpus e sintetiza os critérios qualitativos das categorizações:

Quadro 1 - Categorias de análise

\begin{tabular}{|c|c|c|}
\hline $\begin{array}{c}\text { TIPO DE } \\
\text { LEITURA/ } \\
\text { NÚMERO DE } \\
\text { COMENTÁRIOS }\end{array}$ & CRITÉRIOS DE CATEGORIZAÇÃO & $\begin{array}{c}\text { SUBGRUPOS DE SENTIDO } \\
\text { IDENTIFICADOS }\end{array}$ \\
\hline $\begin{array}{l}\text { Contra-hegemônicas } \\
\text { ( } 275 \text { comentários) }\end{array}$ & $\begin{array}{l}\text { Comentários argumentando que: } \\
\text { - o evento expôs as crianças, } \\
\text { objetificando-as e mercantilizando-as; } \\
\text { - os direitos das crianças e dos } \\
\text { adolescentes foram desrespeitados; } \\
\text { - o evento pode ter causado danos e } \\
\text { efeitos à integridade psíquica dos } \\
\text { participantes; } \\
\text { - "Os fins não poderão justificar os } \\
\text { meios"; } \\
\text { - a adoção deve ser tratada como um ato } \\
\text { de amor e "não como uma mercadoria a } \\
\text { ser buscada numa vitrine". }\end{array}$ & $\begin{array}{l}\text { - Sentidos condenando a } \\
\text { exposição de crianças e } \\
\text { adolescentes aptos à adoção } \\
\text { como se fossem mercadorias em } \\
\text { um evento; } \\
\text { - Sentidos embasados em } \\
\text { aspectos que ferem o Estatuto da } \\
\text { Criança e do Adolescente; } \\
\text { - Sentidos ressaltando os } \\
\text { sentimentos de indignação e } \\
\text { cobrança direcionados às } \\
\text { instituições e à mídia }\end{array}$ \\
\hline $\begin{array}{l}\text { Hegemônicas } \\
\text { ( } 28 \text { comentários) }\end{array}$ & $\begin{array}{l}\text { Comentários argumentando que: } \\
\text { - o evento não teve objetivo de apresentar } \\
\text { crianças e adolescentes a famílias para a } \\
\text { concretização da adoção; } \\
\text { - o objetivo do evento foi promover a } \\
\text { convivência social e mostrar a diversidade } \\
\text { da construção familiar por meio da } \\
\text { adoção; } \\
\text { - as crianças e adolescentes não foram } \\
\text { obrigadas a participar do evento; } \\
\text { - a participação no evento não expôs } \\
\text { crianças e adolescentes, possibilitou } \\
\text { visibilidade à causa da adoção; } \\
\text { - o evento está ocorrendo pela segunda } \\
\text { vez; } \\
\text { - na primeira edição do evento, dois } \\
\text { adolescentes foram adotados; } \\
\text { - eventos semelhantes ocorreram em } \\
\text { outros estados (ES, PE, MG); } \\
\text { - o evento teve autorização judicial; } \\
\text { - repúdio à distorção do evento; } \\
\text { - a adoção tardia é um grande desafio. }\end{array}$ & $\begin{array}{l}\text { - Sentidos associando o desfile à } \\
\text { uma boa iniciativa e à uma } \\
\text { oportunidade } \\
\text { - Sentidos expressando apoio ao } \\
\text { evento utilizando-se } \\
\text { justificativas sentimentais e } \\
\text { religiosas } \\
\text { - Sentidos de confronto às } \\
\text { pessoas que tiveram leituras de } \\
\text { oposição }\end{array}$ \\
\hline
\end{tabular}




\begin{tabular}{|c|c|c|}
\hline $\begin{array}{l}\text { Negociadas } \\
\text { ( } 28 \text { comentários) }\end{array}$ & $\begin{array}{l}\text { Comentários que apresentavam } \\
\text { argumentos dos dois grupos anteriores, } \\
\text { contudo seguidos de ressalvas. Isto é, ao } \\
\text { mesmo tempo que demonstravam algum } \\
\text { alinhamento ao evento, também } \\
\text { apontavam questões negativas sobre a } \\
\text { ação e seus efeitos }\end{array}$ & $\begin{array}{l}\text { - Sentidos de preocupação com } \\
\text { os sentimentos das crianças } \\
\text { - Sentidos de dúvidas, incertezas } \\
\text { quanto ao julgamento moral do } \\
\text { evento } \\
\text { - Sentidos de Propostas de } \\
\text { alternativas para o desfile }\end{array}$ \\
\hline
\end{tabular}

Fonte: elaborado pelos autores

Cabe ressaltar que ao mapear os principais sentidos que envolveram o acontecimento, observamos uma tendência à polarização no âmbito qualitativo; ao passo que, no quantitativo, os comentários de oposição foram mais significativos que os demais. O grande volume de leituras negativas ao evento pode ser resultado de conteúdos que circularam em sites de redes sociais logo após a veiculação da notícia no site Olhar Direto. Identificamos que um deles que alcançou notoriedade foi produzido pela colunista Stephanie Ribeiro, da revista Marie Claire. Sua publicação no Facebook ${ }^{14}$ condenando o desfile teve 4,2 mil compartilhamentos, mais de mil reações negativas e direcionava para a reportagem cujo comentários analisamos.

\subsection{Leituras de oposição ou contra-hegemônicas}

Seguindo o modelo proposto por Hall (2003), fixamos como leitura de oposição os comentários que negam o enquadramento discursivo presente tanto na matéria jornalística como na nota de esclarecimento mencionadas. Percebemos que são predominantes os sentidos de oposição às intenções dos enunciadores. Nos comentários, o público fixa variados adjetivos negativos ao evento: absurdo, bizarro, constrangedor, criminoso, deprimente, desumano, humilhante, inacreditável, irresponsável, lamentável, péssimo, revoltante, ridículo, triste, vergonhoso e vexatório.

As críticas estão centradas na questão da iniciativa de expor crianças e adolescentes mas sobretudo crianças — aptos à adoção como mercadorias em um evento. Contesta-se a ideia do desfile - comumente associado à indústria da moda e usado para exibir produtos à venda, bem como para difundir padrões de beleza - realizado em um estabelecimento comercial como um shopping, símbolo da cultura do consumo (FONTENELLE, 2017). Os comentários questionam a mercantilização da infância e da adolescência promovida no evento Adoção na Passarela, algo considerado incompatível com a causa: “o objetivo de um desfile é

\footnotetext{
${ }^{14}$ Disponível em: https://www.facebook.com/stephanie.ribeiro.93/posts/2223021304458017. Acesso em: 29 mai 2020
} 
vender alguma coisa, por isso se cria uma plateia e um corredor principal: para vender algo. Crianças aptas para adoção NÃO são mercadorias para compradores gostarem ou não"; “Crianças e adolescentes não devem ser expostos dessa forma. [...] Não são mercadoria e a adoção não se dá nesse contexto de relação comercial e aquisição de um bem”.

A intenção dos organizadores de promover um desfile em que crianças e adolescentes teriam um dia diferenciado com produção de "cabelo, roupa e maquiagem" (MERCURI, 2019) como forma de dar "oportunidade de, em um mundo que os trata como se invisíveis fossem, poderem integrar uma convivência social" (OAB-MT, 2019) não foi considerada por parte significativa do público desta categoria. As retóricas de resistência ao evento, ao associarem o acontecimento à mercantilização e objetificação da infância e da adolescência, revelaram referências diferentes das publicadas na nota e na notícia. Identificamos associações do desfile com leilão, feira, vitrine, show e espetáculo. Os comentários acusam os promotores de estarem promovendo a exposição de crianças e adolescentes como objetos, animais, "carnes em um açougue", como ilustram as seguintes falas: "Lamentável, parece exposição de gado, assim poderão escolher, por cor, cabelo, altura, etc.”; “É absurdo que fala né? [...] É com vida que vocês estão brincando, não é carne no açougue para escolher a aparência".

Além da associação do desfile a uma exposição de gado, observamos outros comentários que fazem referência às feiras do período escravocrata brasileiro, ocorridas de meados do século XVI a meados do século XIX. "Atualizaram a feira de escravos? O Shopping virou a praça do Pelourinho??? [...] Que deprimente...”. O trecho revela a capacidade de um acontecimento em despertar ligações com a memória de um povo, produzindo sentidos que convocam o passado para entender o presente (FRANÇA, 2012).

Nas leituras de oposição também percebemos o sentido de indignação e cobrança que aparecem dirigidas à imprensa/mídia, às instituições organizadoras do evento e às entidades responsáveis por defender os direitos da criança e do adolescente. Da sociedade, são cobrados bom senso e criticidade: "cadê o senso crítico da sociedade de Mato Grosso?"; "Não é possível que advogados, assistência social e psicólogos não intervenham neste evento"; "O Conselho Regional de Serviço Social de Mato Grosso pede ajuda da população para barrar esse absurdo! Votem na petição pública que está nesse link [...]”. Da mídia, reclama-se da falta de cobertura adequada sobre o acontecido: "cadê a imprensa de verdade para noticiar isso com as interrogações que realmente cabem nessa situação?". Às entidades que atuam na área dos direitos da infância e adolescência, questiona-se suas omissões: “onde está a 
Promotoria de Defesa da Criança e do Adolescente?”; “cadê o Conselho tutelar?????????”; "como a vara da infância permitiu este ABSURDO????".

Em relação às críticas direcionadas aos promotores do evento, observamos maior ênfase na OAB-MT do que na AMPARA. Os sentidos em torno da OAB-MT estão relacionados à surpresa e repúdio ao fato de a entidade, com relevante histórico na luta pela garantia dos direitos da criança e do adolescente no Brasil e participação na formulação do ECA, ter participado/compactuado com o Adoção na Passarela: "Como assim desfile de crianças para adoção, OAB? Vocês deveriam estar é movendo ação contra isso, não compactuando. O que tá acontecendo, minha gente?", "ECA neste caso não serve pra nada? Então rasga ele e joga fora, OAB!!! Que vergonha a Ordem apoiar e fazer parte de um crime dessa gravidade".

Por fim, ainda nas leituras contra-hegemônicas, constatamos sentidos que fazem oposição ao evento centrando-se no argumento de que ele estaria ferindo a lei, especificamente o ECA, em seus artigos 17 e 18, como aponta o trecho: "Crianças e adolescentes não devem ser expostos dessa forma. É vedado pelo Estatuto da Criança e do Adolescente".

\subsection{Leituras hegemônicas aos organizadores do evento}

Além das leituras de oposição, identificamos um conjunto de depoimentos que classificamos como leituras hegemônicas-dominantes, isto é, comentários que compartilham sentidos semelhantes aos da matéria jornalística e das notas de apoio. Os termos associados ao evento, nos comentários dessa categoria, contribuem para caracterizar positivamente o acontecimento: parabéns, amor, melhor, lindo, maravilhosa iniciativa, ótimo, adorei, alegria, felizes e válida. Destaca-se o frequente uso da palavra iniciativa para caracterizar o acontecimento como algo positivo. Entendemos que esse fato reforça a representação do evento como uma ação social relevante, evitando associá-lo à polêmica da exposição das crianças, tema amplamente condenado pelo público contra-hegemônico.

De modo geral, percebemos que são predominantes posicionamentos que defendem a iniciativa e a justificam utilizando-se de apelos sentimentais. Inferimos que os sentidos ligados à dimensão emocional são estratégias discursivas para sensibilizar os demais leitores em relação ao sofrimento das crianças aptas à adoção e dar ao evento um aspecto mais humanizado. As instituições de acolhimento, por exemplo, são representadas como um lugar 
negativo para as crianças, locais onde elas não deveriam ficar: "Absurdo é ver essas crianças jogadas em abrigos porque pessoas como nós não adotamos"; "Abrigo não é bom para nenhuma criança e se isso for para as crianças serem vistas e conquistar a pessoa que nunca pensou em adotar crianças?".

Cabe notar, nas falas, como o uso do termo abrigo para denominar essas instituições não é aleatória, visto que reforça antigas práticas das instituições dos sistemas de acolhimento de crianças e adolescentes no Brasil que atuavam como "lugares que segrega e inibe a convivência social e comunitária, portanto, prejudiciais ao desenvolvimento humano" (CASSANHA; GARCIA, 2013, p. 19265). Justamente para desconstruir essa imagem, passase a usar o termo instituição de acolhimento a partir da Lei $\mathrm{n}^{\circ} 12010 / 09$, que altera os fundamentos dos abrigos e busca "evitar ou abreviar o abrigamento, que passou a chamar de acolhimento institucional de crianças e adolescentes" (CASSANHA; GARCIA, 2013, p. 19265).

As dificuldades da adoção tardia, principalmente na questão da "falta de interessados" (argumento reforçado na nota da OAB-MT/AMPARA), foram endossadas pelos comentários: "bastante interessante principalmente por dar maior visibilidade a adoção tardia"; "Que Deus lhes abençoe e lhes dê força e ótimas ideias como essa para incentivar a adoção tardia". Esses trechos chamam a atenção para a especificidade da causa do evento, convocando um olhar mais atento a uma situação da dificuldade de adoção entre os 7 e 14 anos, como explicado na notícia em que os comentários foram coletados.

Notamos também, nessa categoria, associações à religiosidade para fundamentar os argumentos de defesa ao evento, como a utilização das palavras: Deus e abençoe. Elas estão presentes nas falas: "Alguém foi adotado? Já tem números? Porque se foi, damos Graças a Deus. Porque na verdade ninguém quer assumir a criação de crianças nessa idade e não sabemos nem onde eles vivem"; "Quantas crianças lindas! Parabéns pela iniciativa! Que Deus lhes conceda muito amor e saúde!"; "Deus abençoe essas crianças que possam encontrar um lar!!". O discurso religioso parece ser um aliado potente para justificar o desfile e rebater suas críticas, reforçando tendências conservadoristas, de parte da sociedade civil, ao pensar em medidas para a adoção (NAKAMURA, 2019).

Nas leituras hegemônicas também percebemos o sentido de confronto às pessoas que fazem um discurso de oposição ao evento. Geralmente, se questiona o fato de os críticos não adotarem as crianças que estavam no desfile: "Seus hipócritas adotem uma só ao invés de ficarem criticando". "Ei você!! Você mesmo que está aí criticando... O que você está fazendo 
por essas crianças??". Também há reclamações que colocam os opositores ao evento como aqueles que distorceram o fato: "Bem, para ser sincero achei muita confusão por questão das pessoas distorcerem os fatos".

\subsection{Leituras negociadas}

$\mathrm{Na}$ análise do corpus, identificamos uma última parcela de comentários que categorizamos como leituras negociadas, por demonstrarem a apreensão dos sentidos propostos pelos enunciadores do evento ao mesmo tempo em que apontam questões negativas sobre a ação e seus efeitos: "Excelente trabalho de incentivar a adoção mas acho que pegou pesado essa passarela, parece que estão expondo as crianças como produto"; "Entendo que a intenção deles foi boa, só creio que não foi exatamente uma forma legal de expor estas crianças".

Identificamos neste grupo a recorrência de palavras como ideia, intenção e entendo, o que demonstra um interesse em encontrar justificações para o desfile. Um aspecto identificado nesse grupo, que não apareceu nas leituras hegemônicas e de oposição, foi a preocupação com os sentimentos das crianças: "Será que não afeta o emocional das crianças?"; "Será que os outros não se sentiram tratados como mercadoria?”; "Quais os estragos psicológicos ficaram para as crianças que se expuseram dessa maneira e não foram adotadas?”. Nesses comentários, observamos o desejo por parte do público de pontuar a necessidade de se afastar da concepção "de criança e adolescente como objeto de livre disposição dos adultos" que pactua "com uma visão de direitos infanto-juvenis anterior à doutrina da proteção integral" (NAKAMURA, 2019, p. 194).

Algumas das falas dessa categoria estão na forma interrogativa, o que caracteriza outro ponto observado na análise: a tendência nas leituras negociadas a levantar dúvidas ("Gostaria de saber mais sobre o projeto") e a revelar incertezas ("O que mais me assusta são os órgãos parceiros do evento. Enfim... Vamos aguardar o posicionamento destes").

Por fim, identificamos comentários que propuseram alternativas para o desfile: "Sou favorável ao evento em si. Poderia ter o que é contado na matéria, como palestras e seminários. Mas poderia haver uma interação com as crianças com os pais e mães adotantes em forma de encontro e dinâmicas"; "acho que eles podiam fazer algo mais voltado para apresentar a história de cada um, seus gostos, seus sonhos, esportes que gostam etc."; "Sei que o objetivo é dar visibilidade a elas, mas acredito que poderiam ter feito de forma 
diferente. Por exemplo, se todos se envolvessem em uma exposição como uma feira de ciências. Elas estariam em grupo, apresentando um trabalho, e as pessoas presentes no evento conheceriam cada uma". Esses trechos revelam a existência de interesse social pela visibilidade da causa da adoção e por problematizar as formas de sua realização, de modo a garantir, como defende Nakamura (2019), que crianças e adolescentes sejam sujeitos da adoção, não o objeto.

\section{CONSIDERAÇÕES FINAIS}

Neste artigo, analisamos os sentidos em torno da participação de crianças e adolescentes no evento Adoção na Passarela, identificando os quadros de leitura nos comentários de uma notícia sobre tal acontecimento. A análise evidenciou que o evento impulsionou um debate acerca do limite tênue entre visibilidade e exposição de crianças e adolescentes aptos à adoção no Brasil, ao engajar públicos distintos que produziram sentidos diversos e constituíram uma arena de disputas.

Os posicionamentos assumidos pelos sujeitos participantes da discussão tendem a se organizar por meio de uma dicotomia entre exposição de crianças e adolescentes (leituras contra-hegemônicas) e visibilidade da causa da adoção (leituras hegemônicas). De um lado, há críticas ao evento por ter exposto crianças e adolescentes a situações constrangedoras e vexatórias, ferindo seus direitos. Do outro lado, há elogios à iniciativa do desfile por ter dado visibilidade à causa da adoção. Sendo assim, por um ângulo, observa-se a crítica à "redução" de crianças e adolescentes à coisa/mercadoria e reivindica-se um olhar para eles como sujeitos de direito que precisam, antes de mais nada, de respeito e proteção nos âmbitos físico, psíquico e moral. Por outro ângulo, vê-se o elogio à divulgação dada pelo evento à problemática da adoção tardia e pleiteia-se um olhar mais atento da sociedade para esse tema premente, embora ignore a "redução", praticada pelo desfile, de crianças e adolescentes a objetos tutelados pelo interesse de adultos em dar visibilidade à causa da adoção.

Nessa perspectiva, os dois blocos de posicionamentos reivindicam, cada um a seu modo, a defesa de direitos de crianças e adolescentes aptos à adoção. Direitos estes de serem: (i) adotados, (ii) respeitados em sua condição humana, (iii) protegidos física, psíquica e moralmente de situações vexatórias e constrangedoras. No entanto, enquanto a leitura hegemônica parece fazer isso por um viés conservador (NAKAMURA, 2019), registrado nos termos que utiliza e nos apelos religiosos que convoca; a conta-hegemônica problematiza 
aspectos humanistas, colocando as crianças e adolescentes como protagonistas do evento e não a prática da adoção a qualquer custo.

A polarização de comentários na matéria faz emergir características do cenário político brasileiro contemporâneo marcado por posicionamentos mais endurecidos entre pensamentos conservadores e progressistas que deu o tom das eleições presidenciais no Brasil em 2018. Isso aponta o potencial do estudo dos acontecimentos e seus desdobramentos em revelar traços de nosso tempo para além do fato analisado, como os valores e as normas sociais. Do mesmo modo que é reflexo de um momento, o acontecimento também interfere tanto sedimentando os sentidos políticos em circulação quanto dando novos contornos aos já circunscritos.

Dessa forma, a produção de sentidos a partir do acontecimento Adoção na Passarela revelou um quadro simbólico complexo que diz sobre o nosso tempo, ao manifestar o reconhecimento da fragilidade na garantia dos direitos de crianças e adolescentes no Brasil. A afetação dos diferentes públicos provocada pelo desfile lançou luz sobre tensões, negociações e reivindicações históricas a respeito do lugar ocupado por crianças e adolescentes, bem como acerca da agenda pública de problemas sociais referentes à infância e à juventude no país.

\section{REFERÊNCIAS}

ABREU, D. Assim falou "O Povo": adoção internacional no dizer jornalístico. In: BARREIRA, I; VIEIRA, S. (orgs.). Cultura e política: tecidos do cotidiano brasileiro. Fortaleza: EUFC, 1998.

AMPARA; OAB-MT. Nota de Esclarecimento. 2019. Disponível em:

<https://www.oabmt.org.br/noticia/15089/nota-de-esclarecimento>. Acesso em: 08 dez. 2019.

AYRES, L. S. M. Adoção e mídia televisiva: a telenovela Amor à vida em análise. Arquivos Brasileiros de Psicologia, n. 68, v. 3, 2016.

ARIÈS, P. História social da criança e da família. Rio de Janeiro: Guanabara, 1981.

BARDIN, L. Análise de conteúdo. 4. ed. Lisboa: Edições70, 2010.

BRASIL. Constituição da República Federativa do Brasil. 1988.

BRASIL. Estatuto da criança e do adolescente. Lei Federal, 1990.

BRASIL. Lei nº 13.509, 2017.

BRASIL. Lei $\mathbf{n}^{\mathbf{0}}$ 12010, 2009.

BUCKINGHAM, D. Crescer na era das mídias eletrônicas. São Paulo: Edições Loyola, 2007. 
CASSANHA, L. A. H.; GARCIA, E. S. De abrigo à casa de acolhimento: a visão dos funcionários. In: XI Congresso Nacional de Educação, 2013, Curitiba. Anais... Curitiba: PUC-PR, 2013. Disponível em: <https://educere.bruc.com.br/CD2013/pdf/10180_5538.pdf〉. Acesso em: 04 dez. 2019.

CONSElHO NACIONAL DE JUSTIÇA. Cadastro Nacional de Crianças Acolhidas. 2020.

Disponível em: <https://www.cnj.jus.br/cadastro-nacional-de-criancas-acolhidas-cnca/> Acesso em: 28 jan. 2020.

COSTA, L. R.; BRAGA, C. F. As representação sociais da adoção: uma análise da mídia impressa no mês nacional da adoção. In: Seminário Nacional de Mídia, Cidadania e Cultura, 2018, Goiânia.

Anais... Goiânia: PPGCOM/FIC/UFG, 2019.

CRP-MT. Conselho Regional de Psicologia de Mato Grosso. CRP 18-MT e CFP emitem nota contra evento "Adoção na Passarela". 2019. Disponível em: <https://crpmt.org.br/noticias/crp-18mt-e-cfp-emitem-nota-contra-evento-adocao-na-passarela>. Acesso em: 08 dez. 2019.

DEFENSORIA PÚBLICA DE MATO GROSSO. Nota de Repúdio. 2019. Disponível em: <http://www.defensoriapublica.mt.gov.br/-/11826341-nota-de-repudio?inheritRedirect=true>. Acesso em: 08 dez. 2019.

DEWEY, J. The public and its problems. Chicago: Swallow Press, 1954.

FONTENELLE, I. A. Cultura do Consumo: fundamentos e formas contemporâneas. Rio de Janeiro: Editora FGV, 2017.

FRANÇA, V. O acontecimento e a mídia. Galáxia (São Paulo, Online), n. 24, 2012.

FRANÇA, Vera Veiga. Paradigmas da comunicação: conhecer o quê?. C-Legenda-Revista do Programa de Pós-graduação em Cinema e Audiovisual, n. 05, 2001.

FRANÇA, V. e ALMEIDA, M. A. V. "O caso Fernanda Karina: as potencialidades do acontecimento". In: VIII Colóquio Brasil França de Ciências da Comunicação e da Informação, Université Stendhal-Grenoble III, Echirolles, França, 2006.

GAGNO, A. P.; WEBER, L. N. D. A adoção na mídia: revisão da literatura nacional e internacional. Paidéia, n. .25, v. 13, 2003. Disponível em: <https://www.scielo.br/scielo.php?pid=S0103863X2003000200010\&script=sci_arttext >. Acesso em: 19 maio 2020.

GAGNO, A. P. O percurso da adoção na imprensa brasileira. Dissertação [Mestrado em Psicologia] - Universidade Federal do Paraná. Curitiba, 2002.

HALL, S. Da Diáspora: identidades e mediações culturais. Belo Horizonte: Ed. da UFMG, 2003.

HEYWOOOD, C. Uma história da infância: da idade média à época contemporânea no ocidente. Porto Alegre: Artmed, 2004.

KRAMER, S. Pesquisando infância e educação: um encontro com Walter Benjamim. In: KRAMER, S; LEITE, M. I. Infância: fios e desafios da pesquisa.Campinas, SP: Papirus, 2008.

MARCÍLIO, M. L. A lenta construção dos direitos da criança brasileira. Século XX. Revista USP, n. 37, p. 46-57, 1998.

MAUX, A. A. B.; DUTRA, E. A adoção no Brasil: algumas reflexões. Estudos e Pesquisas em Psicologia, v. 10, n. 2, p. 356-372, 2010. 
MBAYA, E-R. Gênese, evolução e universalidade dos direitos humanos frente à diversidade de culturas. Estudos Avançados, v. 11, n. 30, p. 17-41, 1997.

MENEGATI, A. F. M.; SOMMER, P. D. Adoção tardia e a dignidade das crianças e adolescentes na fila de espera pela adoção. Revista Jurídica Direito, Sociedade e Justiça, v. 5, n. 1, 2017.

MENESES, S. Acontecimento. In: MELO, J. M.; BARBOSA, M.; MOREIRA, S. V.; HOHLFELD, A (Orgs.). Enciclopédia INTERCOM de comunicação- v. 1. Dicionário brasileiro do conhecimento comunicacional: conceitos (termos, expressões e referências indispensáveis ao estudo da área). 1a.ed.São Paulo: Sociedade Brasileira de Comunicação, 2010.

MERCURI, I. Crianças de 4 a 17 anos participam do evento 'Adoção na Passarela' em shopping da capital. Olhar Conceito, Cuiabá, 20 maio 2019. Disponível em: $<$ https://www.olharconceito.com.br/noticias/exibir.asp?id=17583\&noticia=criancas-de-4-a-17-anosparticipam-do-evento-adocao-na-passarela-em-shopping-da-capital>. Acesso em: 08 dez. 2019.

MOMBERGER, N. F. A publicidade dirigida à crianças e adolescentes: regulamentações e restrições. Porto Alegre: Memória Jurídica Editora, 2002.

NAKAMURA, C. R. Criança e adolescente: sujeito ou objeto da adoção? Reflexões sobre menorismo e proteção integral. Serv. Soc. Soc., São Paulo, n. 134, p. 179-197, 2019. Disponível em: <https://www.scielo.br/pdf/sssoc/n134/0101-6628-sssoc-134-0179.pdf>. Acesso em: 19 maio 2020.

OBSERVATÓRIO DO TERCEIRO SETOR. Adoção no Brasil: a busca por crianças que não existem. 2019. Disponível em: < https://observatorio3setor.org.br/carrossel/adocao-no-brasil-a-buscapor-criancas-que-nao-existem/>. Acesso em: 28 jan. 2020.

OAB-MT, Ordem dos Advogados do Brasil - Seccional Mato Grosso. Cij e Ampara realizam nova edição do 'Adoção na Passarela' no Pantanal Shopping, nesta 3 -feira. 2019. Disponível em: $<$ https://www.oabmt.org.br/noticia/15081/cij-e-ampara-realizam-nova-edicao-do-'adocao-napassarela'-no-pantanal-shopping--nesta-3--feira>. Acesso em: 15 dez. 2019.

QVORTRUP, J. A Infância enquanto categoria estrutural. Educação e Pesquisa, v. 36, n. 2, p. 631643, 2010.

ROSEMBERG, F; MARIANO, C. L. S. A Convenção Internacional sobre os Direitos da Criança: debates e tensões. Cadernos de Pesquisa, v. 40, n. 141, 2010. Disponível em:

<http://www.scielo.br/scielo.php?script=sci_arttext\&pid=S0100-15742010000300003 >. Acesso em: 27 jan. 2020.

UNICEF. Nota do UNICEF sobre o evento Adoção na Passarela. 2019. Disponível em: $<$ https://www.unicef.org/brazil/comunicados-de-imprensa/nota-o-unicef-sobre-o-evento-adocao-napassarela>. Acesso em: 08 dez. 2019.

UNICEF. Convenção sobre os Direitos da Criança. 20-? Disponível e: <https://www.unicef.org/brazil/convencao-sobre-os-direitos-da-crianca >. Acesso em: 27 jan. 2020.

WEBER, L. N. D. Da institucionalização à adoção: um caminho possível. Revista igualdade, v. 9, p. $1-9,1995$.

WEBER, L. N. D. et al. Adoção: pré-conceitos, conceitos e pós-conceitos. In: 46a Reunião Anual da Sociedade Brasileira para o progresso da Ciência, 1994, Vitória. Anais... Vitória, 1994. 
WEBER, L. N. D. e CORNÉLIO, S. A. Adoção: perspectiva dos filhos adotivos. In: X Congresso Latino-Americano de Psiquiatria da Infância e da Adolescência, 1995, Curitiba. Anais... Curitiba, 1995.

WEBER, L. N. D. e GAGNO, A. P. Onde estão os vínculos das crianças institucionalizadas? In: X Congresso latino-americano de psiquiatria da infância e da adolescência., 1995, Curitiba. Anais... Curitiba, 1995.

WEBER, L. N. D. A pesquisa sobre adoção como um fator preventivo. In: XXVI Reunião Anual da Sociedade Brasileira de Psicologia, 1996, Ribeirão Preto. Caderno de Resumos. Ribeirão Preto: SBP, 1996.

WEBER, L. N. D. Laços de ternura: pesquisas e histórias de adoção. Curitiba: Editora Santa Mônica, 1998.

Original recebido em: 30 de janeiro de 2020

Aceito para publicação em: 30 de junho de 2020

Andrielly Silva Ramos de Sene

Graduanda de Comunicação Social - Publicidade e Propaganda na Universidade Federal de Mato Grosso (UFMT). Bolsista do Programa de Iniciação Científica (UFMT). Integrante do OPS Observatório de Publicidade e Sociedade (UFMT). Técnica em Eventos pelo Instituto Federal de Educação, Ciência e Tecnologia de Mato Grosso (IFMT).

\section{Dôuglas Aparecido Ferreira}

Professor da Faculdade de Comunicação e Artes da Universidade Federal de Mato Grosso.

Doutorando em Comunicação Social na Universidade Federal de Minas Gerais. Mestre em Comunicação Social - Interações Midiáticas pela Pontifícia Universidade Católica de Minas Gerais (2015) com período de intercâmbio na Ural Federal University (UrFU - Ecaterimburgo - Rússia) para cursar disciplinas no Departamento de Comunicação de Marketing e Branding. Especialista em Gestão de Marcas e Identidade Corporativa pela Pontifícia Universidade Católica de Minas Gerais (2013) e bacharel em Comunicação Social (Gestão da Comunicação Integrada) - Habilitado em Publicidade e Propaganda pela Pontifícia Universidade Católica de Minas Gerais (2009). Membro do GRIS - Grupo de Pesquisa em Imagem e Sociabilidade (UFMG). Vencedor do Prêmio ABRAPCORP de Teses e

Dissertações em 2017.

\section{Pâmela Saunders Uchôa Craveiro}

Professora do Programa de Pós-Graduação em Comunicação da Universidade Federal de Mato Grosso (UFMT). Doutora e mestra em Comunicação pela Universidade de Vigo (UVIGO-Espanha), com pós-doutorado em Comunicação pela Universidade Federal Fluminense. Graduada em

Comunicação Social - Publicidade e Propaganda pela Universidade Federal do Ceará (UFC). Pesquisadora dos grupos de pesquisa, certificados pelo CNPq: CICLO - Comunicação, Política e Cidadania (UFMT), ESC - Ética na Sociedade do Consumo (UFF) e LabGrim - Laboratório de 
PROGRAMA DE PÓS-GRADUAÇÃO EM COMUNICAÇÃO DA UNIVERSIDADE FEDERAL DE SANTA MARIA

Estudos da Relação Infância, Juventude e Mídia (UFC). Coordenadora do OPS - Observatório de Publicidade e Sociedade.

\section{(c) $(1)(0)$}

Esta obra está licenciada com uma Licença

Creative Commons Atribuição-NãoComercial-CompartilhaIgual 4.0 Internacional 